\title{
Electrophysiological correlates of semantic processing in Williams syndrome
}

\author{
Ana P. Pinheiro ${ }^{\mathrm{a}, *}$, Santiago Galdo-Álvarez ${ }^{\mathrm{b}}$, Adriana Sampaio ${ }^{\mathrm{a}}$, \\ Margaret Niznikiewicz ${ }^{c}$, Oscar F. Gonçalves ${ }^{a}$ \\ ${ }^{a}$ Neuropsychophysiology Lab, CiPsi, School of Psychology, University of Minho, Braga, Portugal \\ ${ }^{\mathrm{b}}$ Clinical Psychology and Psychobiology Department, University of Santiago de Compostela, Santiago de Compostela, Spain

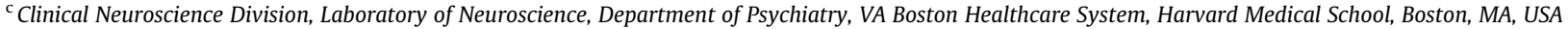

\section{A R T I C L E I N F O}

Article history:

Received 5 June 2010

Received in revised form 15 June 2010

Accepted 21 June 2010

\section{Keywords:}

Williams syndrome

Language

Semantic processing

Event-related potentials

Neurodevelopment

\begin{abstract}
A B S T R A C T
Williams syndrome (WS), a genetic neurodevelopmental disorder due to microdeletion in chromosome 7 , has been described as a syndrome with an intriguing socio-cognitive phenotype. Cognitively, the relative preservation of language and face processing abilities coexists with severe deficits in visual-spatial tasks, as well as in tasks involving abstract reasoning. However, in spite of early claims of the independence of language from general cognition in WS, a detailed investigation of language subcomponents has demonstrated several abnormalities in lexical-semantic processing. Nonetheless, the neurobiological processes underlying language processing in Williams syndrome remain to be clarified. The aim of this study was to examine the electrophysiological correlates of semantic processing in WS, taking typical development as a reference. A group of 12 individuals diagnosed with Williams syndrome, with age range between 9 and 31 years, was compared with a group of typically developing participants, individually matched in chronological age, gender and handedness. Participants were presented with sentences that ended with words incongruent (50\%) with the previous sentence context or with words judged to be its best completion (50\%), and they were asked to decide if the sentence made sense or not. Results in WS suggest atypical sensory ERP components (N100 and P200), preserved N400 amplitude, and abnormal P600 in WS, with the latter being related to late integration and re-analysis processes. These results may represent a physiological signature of underlying impaired on-line language processing in this disorder.
\end{abstract}

(c) 2010 Elsevier Ltd. All rights reserved.

\section{Introduction}

Williams syndrome (WS), a rare neurodevelopmental disorder characterized by a deletion on chromosome 7 q11.22-23, has called the attention of researchers due to its intriguing phenotype in which an apparent preservation of language and face processing seems to coexist with severe intellectual deficits in other cognitive domains such as visual-spatial processing and executive functioning (Bellugi, Lichtenberger, Jones, Lai, \& St. George, 2000; see Martens, Wilson, \& Reutens, 2008, for a review). This syndrome was initially proposed as a paradigmatic example of cognitive dissociation and of a modular organization of the brain and, more specifically, an example of the independence of language from general cognition (Bellugi,

\footnotetext{
* Corresponding author at: Neuropsychophysiology Lab, CIPsi, School of Psychology, University of Minho, Campus de Gualtar, $4710-057$ Braga, Portugal. E-mail address: ana.pinheiro@psi.uminho.pt (A.P. Pinheiro).
} 
Bihrle, Jernigan, Trauner, \& Doherty, 1990; Bellugi, Bihrle, Neville, Jernigan, \& Doherty, 1992; Bellugi, Marks, Bihrle, \& Sabo, 1988; Pinker, 1994).

In fact, when compared with other developmental disorders such as Down syndrome (DS) there is evidence for increased verbal production in WS (e.g., Mervis \& Robinson, 2000). Other aspects of language production, such as affective prosody and the use of audience hookers, seem to be not very different from typically developing chronological age matched controls (Gonçalves et al., 2004, 2010; Jones et al., 2000; Reilly, Klima, \& Bellugi, 1991). Additionally, WS verbal abilities seem to develop at a faster rate than their nonverbal abilities (Jarrold, Baddeley, \& Hewes, 1998).

However, contrary to initial claims of modular language preservation, recent studies show that language abilities are below age-appropriate levels (Grant, Valian, \& Karmiloff-Smith, 2002; Landau \& Zukowski, 2003; Laws \& Bishop, 2004; Lukács, Pléh, \& Racsmány, 2004; Phillips, Jarrold, Baddeley, Grant, \& Karmiloff-Smith, 2004; Pléh, Lukács, \& Racsmány, 2003; Sullivan, Winner, \& Tager-Flusberg, 2003; Vicari et al., 2004) and follow an atypical developmental pathway (e.g., Laing et al., 2002; Mervis \& Bertrand, 1997; Mervis et al., 2003). It appears that some subcomponents (receptive vocabulary, phonological short-term memory, regular morphology, production of affective prosody) are relatively more preserved than others (e.g., repetition of syntactically complex sentences, production of grammatical gender, irregular morphology, comprehension of spatial terms, comprehension of figurative language, pragmatics) (see Brock, 2007, for a review).

There is less agreement in the literature when it comes to semantic fluency. While some studies suggest a higher production of words in semantic fluency tasks in WS individuals than would be expected for their average mental age along with an increased production of atypical category exemplars (e.g., Bellugi et al., 1990, 1992, 1988; Bellugi, Wang, \& Jernigan, 1994; Rossen, Klima, Bellugi, Bihrle, \& Jones, 1996; Wang \& Bellugi, 1993), others suggest that this is not the case (Jarrold, Hartley, Philipps, \& Baddeley, 2000; Johnson \& Carey, 1998; Scott et al., 1995; Stevens \& Karmiloff-Smith, 1997; Volterra, Capirci, Pezzini, Sabbadini, \& Vicari, 1996).

There is a similar lack of consensus in relation to semantic priming. Some studies found the same effects of priming on reaction times of individuals with WS and controls (e.g., Tyler et al., 1997), which may suggest a normal organization of semantic system in WS. However, other studies suggested abnormal lexical knowledge in WS (e.g., Bellugi et al., 1988, 1990; Jarrold et al., 2000; Johnson \& Carey, 1998; Rossen et al., 1996; Volterra et al., 1996; Ypsilanti, Grouios, Alevriadou, \& Tsapkini, 2005), as well as deficits in lexical access (e.g., Bromberg, Ullman, Marcus, Kelly, \& Levine, 1995; Temple, Almazan, \& Sherwood, 2002; Ypsilanti, Grouios, Zikouli, \& Hatzinikolaou, 2006). This finding led some authors to propose a dissociation between preserved structure of semantic memory and impairment in the integration of word meanings into online developing sentential representations (Tyler et al., 1997).

The impairments found in semantic memory may be explained by a lack of maturity in conceptual organization of semantic categories (e.g., Jarrold et al., 2000; Johnson \& Carey, 1998) in the sense that individuals with WS can put information in semantic networks but might have difficulties in conceptually reorganising this information. This hypothesis seem to be corroborated by studies showing a decreased sensitivity to word frequency in WS and a nearly equal preference for primary and secondary meaning of homonyms (Rossen et al., 1996), a trend for the production of infrequent words towards the end of a trial in semantic fluency tasks (Rossen et al., 1996), or an atypical semantic development in the sense that older individuals with WS do not present a more sophisticated conceptual structure than younger individuals (Jarrold et al., 2000).

Together, these findings question the claim for a modular preservation of language in WS. It is possible that the idea of the intact language may have arisen from the comparisons with DS where more severe language impairment is observed (e.g., Mervis, 2003). Another contributing factor may have been the techniques used to study this genetic disorder. Most studies used behavioral measures to probe language function in WS. While these are valuable studies, they preclude observation of neural processes that underlie language performance. Both reaction times and error rates are, by definition, aggregate measures of all processes that went into making a response. As such they do not provide information about possible abnormalities at different stages of information processing prior to the response. Thus, a more comprehensive approach to the study of language in both normal and clinical population is the concurrent use of behavioral and event-related potential techniques (e.g., Hsu, Karmiloff-Smith, Tzeng, Chin, \& Wang, 2007).

Event-related potential (ERP) techniques are one of the few methodologies that document real time changes in neurocognitive processes. As such they are a valuable supplement to the study of language (Kutas \& Federmeier, 2000). One of the components that has been associated with language processing in numerous studies is the N400, a negative going potential that peaks around $400 \mathrm{~ms}$ after the presentation of visual stimuli, and around 300-350 ms to auditorily delivered stimuli (see Lau, Philipps, \& Poeppel, 2008, for a review). The N400 has been found sensitive to processing semantic information regardless of the physical nature of the stimulus, i.e., it has been found to both visual and auditory language stimuli (e.g., Anderson \& Holcomb, 1995; Besson \& Macar, 1986; Kutas \& Iragui, 1998; Niznikiewicz et al., 1997) as well as to pictures (e.g., Coch, Maron, Wolf, \& Holcomb, 2002; Federmeier \& Kutas, 2002; West \& Holcomb, 2002; Willems, Özyürek, \& Hagoort, 2008). It seems to reflect the ease with which two concepts can be linked together and as such it has been used as an index of priming and context use (e.g., Brown \& Hagoort, 1993; Federmeier \& Kutas, 1999a,b; Halgren, 1990; Kutas \& Hillyard, 1980, 1984; Rugg, Doyle, \& Holdstock, 1994; Van Petten, 1993). The N400 has been found to peak maximally at centro-parietal electrodes and is more negative going to words or pictures that do not fit well the proceed context relative to these semantic items that fit the previous context well. In addition, its amplitude can be influenced by word frequency, word type (e.g., closed vs. open class), word lexical status, or the semantic or associative relationship between words, but it is insensitive to decision-related and response-selection mechanisms (Heinze, Muente, \& Kutas, 1998). Therefore, the N400 component may be a good probe to study language processes in WS. 
In addition to N400, other components have been studied in language paradigms. Specifically, the N100, P200, and N250 have been proposed as correlates of initial, more sensory based processes (Barnea \& Breznitz, 1998; Hagoort \& Brown, 2000; Niznikiewicz \& Squires, 1996; Liu, Perfetti, \& Hart, 2003; van den Brink, Brown, \& Hagoort, 2001; Van Petten, Coulson, Rubin, Plante, \& Parks, 1999) and a later component, P600, was also extensively studied as a correlate of late integration processes (e.g., Friedman, Simson, Ritter, \& Rapin, 1975; Kramer \& Donchin, 1987; Osterhout \& Holcomb, 1992).

Developmentally, studies using connected speech found that an N400 with an adult-like pattern, in terms of amplitude, is observed by age 7 (Cummings, Ceponiene, Dick, Saygin, \& Townsend, 2008; Hahne, Eckstein, \& Friederici, 2004), although there is a decrease in latency as a function of age, with 10-year-old children showing N400 latency similar to adults (Hahne et al., 2004). Other studies found marked reductions in latency and amplitude from 5 until 15 to 16 years of age, with the largest N400 effects being observed for 5- to 6-year-old children (Holcomb, Coffey, \& Neville, 1992).

Language studies in WS using auditory sentences suggested ERP abnormalities in early components within N1 and P2 latency. More positive P200 amplitude during auditory sentences processing was reported by Neville, Mills, and Bellugi (1994). In the same study, a larger positivity to congruous words in auditory sentences was observed in WS adults and children relative to normal age matched controls, over the left hemisphere. This was related with larger amplitude of the N400 response (i.e., difference between congruent and incongruent sentence endings) in WS adults than in normal comparison participants. This finding was interpreted as reflecting atypical semantic activation (enhanced connections between related lexical items) which, at the behavioral level, was associated with the unusual performance in semantic fluency tasks, commonly described in this population such as, for instance, the retrieval of atypical members of a given semantic category (Neville et al., 1994).

A second ERP study in WS (St. George, Mills, \& Bellugi, 2000) also showed differences in the N400 response, with this being larger in WS relative to normal controls and with a bilateral distribution. In addition, the WS group did not show a greater early left anterior negativity to function words and later posterior negativity (N400) to content words (relative to function words) found in normal comparison participants. Abnormalities in the earlier ERP components were also found by Mills et al. (2003) to auditorily presented sentences. These authors reported an atypical "W" pattern (small N1, large P1/P2) linked to the processing of auditory linguistic information, in the WS group (8-year-olds and older participants), but not in any normal control age groups. These findings were interpreted as suggestive of hyper-activation within the auditory system.

In spite of the contributions of the studies described above, the neural and cognitive mechanism(s) that lead to language difficulties in WS have yet to be elucidated. One hypothesis suggests that atypical performance in some language tasks may reflect too broad spread of activation in the semantic networks, which could account for the activation of weakly associated items. A second hypothesis suggests that these abnormalities reflect a failure to use verbal context in order to modulate the initial semantic activation appropriately, pointing to deficits in later executive functions.

Unfortunately, the few studies on N400 in WS do not provide enough details about experimental procedures and results analysis to be able to understand the source of discrepancy between the studies.

The aim of the present study was to investigate the electrophysiological correlates of semantic processing in WS using auditory sentences. More specifically, we aimed at characterizing the temporal course of processing congruent and incongruent sentence endings, examining early auditory ERP responses (N100 and P200), ERP responses related to semantic integration (N400), and ERP responses related to semantic and syntactic integration or re-analysis processes (P600).

Based on previous studies (Neville et al., 1994; Mills et al., 2003; St. George et al., 2000), we predicted that processes of semantic integration would be preceded by abnormalities in early ERP components: reduced N100 and enhanced P200 amplitude. Also if, as suggested in the literature, individuals with WS have difficulties integrating context efficiently, more negative N400 amplitude to congruent and incongruent endings would be expected. Difficulties with syntactic and semantic integration and comprehension would be indexed by more positive P600 amplitude in WS for both types of sentence endings.

In order to address these hypotheses, 12 participants with WS and 12 typically developing individuals were presented with auditory sentences in two conditions: (1) sentences ending with an expected and valid word; and (2) sentences ending with an invalid word given its previous semantic context.

\section{Methods}

\subsection{Participants}

A group of 12 participants ( 5 females and 7 males), diagnosed with WS, with age range between 9 and 34 years $(M=17.3$; $\mathrm{SD}=6.50)$, was compared with a typically developing group, individually matched for chronological age $(M=17.3$; $\mathrm{SD}=6.50$ ), gender and handedness. Participants were matched for chronological age rather than mental age for several reasons. First, our major aim was to compare a group of individuals with WS to a group of typically developing individuals and to understand which differences exist in the ERP responses to auditory language stimuli in WS and, in particular, what is deviating from typical development. Second, studies suggest differences in amplitude and latency in language ERP components throughout development. For example, N400 seems to be well established around age 7 (Cummings et al., 2008 ; Hahne, Eckstein, \& Friederici, 2004). Matching participants with WS and controls on MA would result in comparing these participants with younger age groups, so that potential differences could be due to the age of participants and not to the cognitive processes underlying the ERP responses. Third, control participants who are matched on IQ (e.g., Down syndrome or nonspecific mental retardation) generally have language abilities that are inferior to those of individuals with WS. 
Participants with WS were recruited at a large Genetic Medical Institute in Oporto, Portugal, and also in collaboration with the Portuguese Williams Syndrome Association. WS diagnoses were made by fluorescent in situ hybridization (FISH) confirmation of elastin gene deletion (Korenberg et al., 2000). Exclusion criteria were: (a) the presence of severe sensory (e.g., hearing problems) or speech disorder; (b) co-morbidity with severe psychopathology not associated with the syndrome; (c) use of any medication that might affect cognitive function or electroencephalogram (EEG) recordings, such as steroids and barbiturates; (d) and use of any psychoactive medication. Controls were typically developing individuals without evidence of sensory, psychiatric, neurological disorder or cognitive impairment. All participants were right-handed, according to the Edinburgh handedness inventory (Oldfield, 1971) and had European Portuguese as their first language. Each participant and their guardians (in the case of minor participants and patients) gave written informed consent for their participation in the study via consent forms, after a detailed description of the study. The Ethics Committee of the University of Minho approved this study.

The mean socioeconomic status, as measured by an adapted version of Graffar Scale (Graffar, 1956) was 3.00 (SD =1.28) for the Williams syndrome group and 2.92 ( $S D=1.44$ ) for the typically developing (TD) control group. The two groups did not differ in socioeconomic status $(t(22)=-0.15, p>.05)$. However, as expected, groups differed in mean years of education $(t(22)=2.76, p=.011)$, with more years of education in the TD group $(M=10.83 ; \mathrm{SD}=3.66)$ than in WS $(M=7.58 ; \mathrm{SD}=1.78)$.

To assess general cognitive functioning (Full Scale IQ), participants with chronological age between 9 and 16 years were administered the Portuguese version of the Wechsler Intelligence Scale for Children - Third Edition (WISC-III) (Wechsler, 1991), while participants over 16 years old were administered the Wechsler Adult Intelligence Scale - Third Edition (WAISIII) (Wechsler, 1997). Since the experimental task in this study was auditory, the following measures of auditory (phonological) processing were used, selected from the Portuguese version of Psycholinguistic Assessment of Language Processing in Aphasia - PALPA (Castro et al., 2007): Discrimination of Minimal Pairs in Pseudowords; Auditory Lexical Decision and Morphology, Repetition of Pseudowords. Neurocognitive tests were in the native language of the patients and were administered and scored accordingly. Results of general cognitive assessment are presented in Table 1.

Mean distribution of Full Scale Intelligence Quotient (FSIQ) in WS was found to be within the moderate mental retardation interval, with verbal intelligence quotient (IQ) slightly higher than performance IQ.

In order to test for group differences on neurocognitive and language measures, $t$-tests were computed. As seen in Table 1 , groups were different on all measures, with the exception of auditory lexical decision and morphology, for derivated words. Also, it is worth noting that groups were only marginally different during discrimination of minimal pairs in pseudowords, for similar and different pairs.

\subsection{Stimuli}

Eighty-eight sentences, each one composed by five words, were developed and presented auditorily.

The choice of the simplest syntactic structure and reduced number of words was due to the difficulties shown by individuals with WS in interpreting more complex sentences (e.g., Grant et al., 2002; Landau \& Zukowski, 2003; Lukács, Pléh, \& Racsmány, 2004; Vicari et al., 2004) and as a way of minimising working memory demands (see Tyler et al., 1997).

The set of experimental sentences was developed after an earlier study that established cloze probability for the sentence final words (see Appendix A). The cloze probability study was conducted using 11 groups of children and adolescents $(N=192)$, from 2 nd to 12 th grades (early middle school, middle school, late middle school, and high school), with ages ranging between 6 and 18 years old. These participants were asked to complete a set of 73 sentence contexts with the first

Table 1

Results of the neurocognitive assessment of Williams syndrome (WS) and typically developing (TD) groups.

\begin{tabular}{|c|c|c|c|}
\hline & WS group $(N=12)$ Mean $(\mathrm{SD})$ & TD group $(N=12)$ Mean $(\mathrm{SD})$ & Significance test $t(p)$ \\
\hline \multicolumn{4}{|c|}{ 1. Global intellectual functioning } \\
\hline Verbal IQ & $58.55(9.18)$ & $116.45(14.75)$ & $11.05\left(.000^{* *}\right)$ \\
\hline Performance IQ & $52.18(5.96)$ & $111.73(16.32)$ & $11.37\left(.000^{* *}\right)$ \\
\hline Full Scale IQ & $51.55(7.10)$ & $114.00(13.71)$ & $13.52\left(.000^{* *}\right)$ \\
\hline \multicolumn{4}{|c|}{$\begin{array}{l}\text { 2. Language (phonological processing) } \\
\text { (a) Discrimination of minimal pairs in pseudowords }\end{array}$} \\
\hline Similar pairs & $31.44(0.73)$ & $31.92(0.29)$ & $2.06(.053)$ \\
\hline Different pairs & $29.44(3.71)$ & $31.67(0.49)$ & $2.07(.053)$ \\
\hline \multicolumn{4}{|c|}{ (b) Auditory lexical decision and morphology } \\
\hline Regular words & $12.38(2.45)$ & $14.67(0.89)$ & $3.00\left(.008^{*}\right)$ \\
\hline Derivated words & $12.25(3.24)$ & $13.92(1.31)$ & $1.61(.124)$ \\
\hline \multicolumn{4}{|c|}{ (c) Repetition of pseudowords } \\
\hline 1. Syllable & $8.88(1.13)$ & $9.75(0.45)$ & $2.44\left(.025^{*}\right)$ \\
\hline 2. Syllables & $8.63(2.07)$ & $10.00(0.00)$ & $2.34\left(.031^{*}\right)$ \\
\hline 3. Syllables & $8.38(0.92)$ & $10.00(0.00)$ & $6.23\left(.000^{* *}\right)$ \\
\hline
\end{tabular}


Table 2

Psycholinguistic characterization (duration, length, age of acquisition, familiarity, concreteness, and imageability) of congruent and incongruent targets.

\begin{tabular}{lll}
\hline Variable & \multicolumn{2}{c}{ Sentence ending } \\
\cline { 2 - 3 } & Congruent mean (SD) & Incongruent mean (SD) \\
\hline Duration (sec) & $2.45(0.39)$ & $2.33(0.31)$ \\
Length (letters) & $5.51(1.63)$ & $5.55(1.96)$ \\
Age of acquisition & $2.02(0.60)$ & $2.25(0.61)$ \\
Familiarity & $1.55(0.38)$ & $1.70(0.39)$ \\
Concreteness & $5.96(1.27)$ & $5.93(1.13)$ \\
Imageability & $6.00(1.16)$ & $5.77(1.29)$ \\
\hline
\end{tabular}

Data were collected from European Portuguese lexical databases (Marques et al., 2007; Nascimento, Casteleiro, Marques, Barreto, \& Amaro, no date).

word that came to their mind. Cloze probability of the words selected by the majority of participants was then computed. For the incongruent condition, a set of words was selected, after controlling for psycholinguistic variables (age of acquisition, familiarity, frequency, length, number of syllables, concreteness, imageability), in order to complete the same sentence contexts but now in a semantically anomalous way. All sentences (congruent and incongruent) were presented to a different group of children and adolescents, from 2nd to 12th grades (190 participants), who were asked to judge if the sentences made sense or not. After the analysis of their plausibility ratings, 49 congruent and incongruent sentences endings were selected ( 44 for the experimental list and 5 for the training session). The sentence was selected if at least $95 \%$ of the participants rated the sentence as correct or incorrect.

The sentences were then recorded by a female native speaker of European Portuguese, with emotionally neutral intonation, in a sound proof room with an Edirol R-09 recorder and a CS-15 cardioid-type stereo microphone, with a sampling rate of $22 \mathrm{kHz}$ and 16-bit quantization.

The stimuli were divided into four blocks (22 sentences each). The sentences were pseudo-randomized across blocks, in order to avoid presenting the same sentence twice within the same block. Following Kutas and Hillyard's (1980) paradigm, half of the sentences ended with words incongruent with the previous sentence context (e.g., The girl curls her biscuit) and half ended with a word judged to be the best completion (e.g., The girl curls her hair). The final words had a mean length of 5.53 letters across conditions (congruent and incongruent sentence endings) and had low age of acquisition (Marques, Fonseca, Morais, \& Pinto, 2007) (see Table 2). No critical word was repeated within and between blocks.

No differences were found between critical words of both conditions in any of the measured psycholinguistic variables.

\subsection{Procedure}

Each participant was seated comfortably in a reclining chair in a sound-attenuating chamber. All sentences were presented binaurally through headphones using Presentation software (www.neurobs.com) at a sound level that was rated as comfortable for each participant (60 dB SL), with a mean duration of $2390 \mathrm{~ms}$, one word about every $598 \mathrm{~ms}$. Sentences were presented in four blocks with short breaks offered between them (about $5 \mathrm{~min}$ ). A monitor with a resolution of 1,024 3 768 and a refresh rate of $60 \mathrm{~Hz}$ was used to display a fixation cross. The distance between the participants and the computer screen was about $100 \mathrm{~cm}$. Participants were instructed to decide if the last word was a good completion for a given sentence by pressing one response button for "yes" and another one for "no". The mapping between response and right or left hand was counterbalanced across participants. Half of the participants pressed a button with their right hand for congruent sentences and with their left hand for incongruent sentences, and the other half pressed a button with their left hand for congruent sentences and with their right hand for incongruent sentences.

A visual cue presented in the middle of the computer screen for $2000 \mathrm{~ms}$ and a warning signal preceded the presentation of each sentence. A fixation cross remained on the screen while participants were listening to the sentences, to minimize eye movements. Each sentence was followed with a visual cue lasting for $5000 \mathrm{~ms}$ to remind participants to press a response button. The next trial started $100 \mathrm{~ms}$ after the response was made. As soon as the subject pressed a button, and after an interstimulus interval of $100 \mathrm{~ms}$, the next trial started. The maximum time between the offset of one sentence and the onset of the following sentence was $5100 \mathrm{~ms}$.

Prior to the experimental procedure, participants were exposed to a short practice (five sentences) designed to reiterate the instructions and to acclimate participants to the task.

Accuracy data (number of hits) were recorded. Hits were defined as the number of correct responses made after the appearance of the prompt to make a response.

\subsection{Data acquisition and analysis}

\subsubsection{EEG data acquisition and analysis}

While participants were listening to sentences, the EEG was recorded using a 32-channel QuickAmp amplifier (www.brainproducts.com) with $20 \mathrm{Ag}-\mathrm{AgCl}$ electrodes mounted in an elastic cap (Easy Cap), according to the 10-20 System 
(Jasper, 1958). The set of 20 electrodes included: Fp1, Fp2, Fz, F3, F4, F7, F8, Cz, C3, C4, T7, T8, Pz, P3, P4, P7, P8, Oz, O1, and O2. Additional bipolar electrodes placed at the external canthi of both eyes were used to record horizontal eye movements. Vertical eye movements were monitored with electrodes placed at left supra- and infraorbital sites. Average reference was used during EEG acquisition, with forehead as ground electrode. Impedance levels were kept at or below $5 \mathrm{~K} \Omega$ at all electrode locations. The EEG was digitized on-line at a sampling rate of $250 \mathrm{~Hz}$ and stored on a computer disk for off-line processing. EEG data were analyzed using Brain Analyzer software (www.brainproducts.com). Separate individual average waveforms were constructed to congruent and incongruent sentence endings, with $100 \mathrm{~ms}$ baseline and $900 \mathrm{~ms}$ epoch, post-stimulus onset. The Gratton, Coles, and Donchin (1983) algorithm was used to remove contamination from eye movements. Single sweeps were rejected if the amplitude at any electrode site exceeded $\pm 75 \mathrm{mV}$. Data from three participants (one from WS group and two typically developing controls) were discarded due to excessive artifacts. On average, 43 (SD = 3.91) epochs out of 44 possible trials were retained after artifact rejection.

\subsubsection{Statistical analysis}

Statistical analyses were conducted separately for behavioral and ERP data. Accuracy rates were calculated for each participant as the number of correctly performed trials within each condition (congruent vs. incongruent) relatively to all trials in that condition. Only data from participants who judged sentence appropriateness in each experimental condition above chance level were included in ERP analyses.

Behavioral data were analyzed according to repeated-measures analyses of variance, with condition (congruent vs. incongruent) as within-participants factor, and group (WS vs. typically developing controls - TD) as between-participants factor.

After the inspection of the individual and grand average waveforms, four components were selected for analysis in order to provide a comprehensive description of processes associated with sentence analysis at a neuronal level: N100, P200, N400, and P600. Based on the inspection of individual averages and grand averages, the N100 was measured as the most negative voltage within the latency of 80 and $160 \mathrm{~ms}$, the P200 was measured as the most positive voltage within the latency of 160 and $260 \mathrm{~ms}$, and the $\mathrm{N} 400$ was measured as the most negative deflection within the latency window of 300 and $450 \mathrm{~ms}$. The latency of the N400 measuring window is in agreement with previous studies reporting an earlier onset of the N400 effect for auditorily presented language stimuli (e.g., Holcomb \& Neville, 1990). Finally, P600 was measured as mean amplitude in two latency windows: 500-600 and 600-700 ms. Peak and mean amplitudes respect to baseline were measured at all selected electrode locations.

In order to provide a comprehensive analysis of the ERP differences between the two groups under study, a region analysis was conducted, using repeated-measures analyses of variance (ANOVA) separately for amplitude and latency, with sentence condition (congruent vs. incongruent), region (frontal vs. central vs. parietal), and electrodes (Fz, F3, F4; Cz, C3, C4; $\mathrm{Pz}, \mathrm{P3}, \mathrm{P} 4)$ as within-participants factors, and group (WS vs. TD) as between-participants factor. Also, in order to test for hemispheric differences, an additional analysis was conducted, using sentence condition (congruent vs. incongruent), hemisphere (left vs. right) and electrodes (F3, C3, P3; F4, C4, P4) as with-participants factors, and group as betweenparticipants factor.

The p-values in analyses of variance (ANOVA) with within-subject factors are reported before Greenhouse-Geisser Epsilon correction (Geisser \& Greenhouse, 1959). Post hoc tests were conducted for significant main effects and interactions, using pairwise comparisons, with Bonferroni correction.

\section{Results}

\subsection{Behavioral results}

Mean number of correct responses for individuals with WS and controls for the two target conditions (congruent vs. incongruent) is presented in Table 3. Data from one participant from the WS group (the youngest subject) was excluded, because he did not discriminate between the response buttons. The results indicate a high rate of correct responses for both groups, showing that participants were paying attention to the stimuli and were able to make a congruency judgment.

There was a significant effect of condition on the number of correct responses $(F(1,21)=6.45, p=.019)$, with correct response rate significantly higher for congruent than for incongruent sentence endings. A trend for a main group effect was observed $(F(1,21)=4.22, p=.053)$, suggesting more correct responses in the TD group relative to WS.

Table 3

Mean number of correct responses, by group and sentence condition.

\begin{tabular}{|c|c|c|c|c|c|c|}
\hline \multirow[t]{3}{*}{ Target } & \multicolumn{6}{|c|}{ Group } \\
\hline & \multicolumn{3}{|c|}{ Williams syndrome $(n=11)$} & \multicolumn{3}{|c|}{ Typically developing controls $(n=12)$} \\
\hline & Mean & SD & Range & Mean & SD & Range \\
\hline Congruent & 40.27 & 4.54 & $29-43$ & 42.92 & 1.12 & $41-44$ \\
\hline Incongruent & 41.82 & 3.13 & $33-44$ & 43.58 & 0.67 & $42-44$ \\
\hline
\end{tabular}



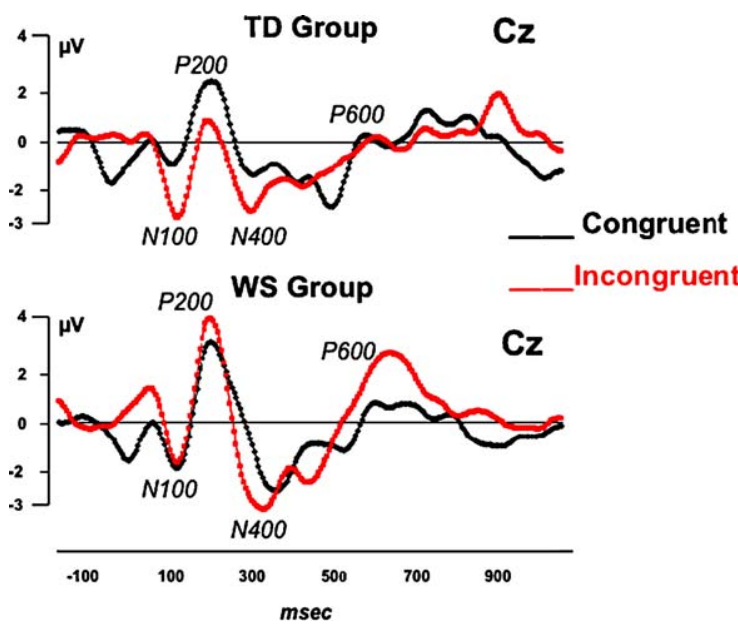

Incongruent

Fig. 1. Grand averages waveforms for congruent and incongruent sentence endings in WS and TD groups (selected electrode: $\mathrm{Cz}$ ).

\subsection{ERP results}

Fig. 1 shows Grand Average waveforms at $\mathrm{Cz}$ in both groups, for congruent and incongruent conditions. ERP group contrasts are shown separately for congruent and incongruent sentence endings in Fig. 2A and B.

In the following sections, amplitude and latency results will be described separately for each ERP component. Only significant main effects and interactions are reported.

In order to control for chronological age and IQ effects, a multivariate general linear model was used, adding chronological age and IQ as covariates. No significant effects of age $(F(1,16)=0.93, p=.685)$ and $\operatorname{IQ}(F(1,16)=2.44, p=.469)$ were found.

\subsection{1. $N 100$}

A repeated measures ANOVA showed a significant interaction of sentence condition $\times$ region $\times$ group $(F(2,38)=3.85$, $p=.051)$. A difference between sentence conditions was found only in the TD group, with more negative N100 for incongruent relative to congruent sentence endings, at frontal and central electrodes. In addition, repeated measures ANOVA testing for hemispheric differences in N100 amplitude showed a significant interaction of sentence condition $\times$ hemisphere $\times$ group $(F(1,19)=5.08, p=.036)$ : N100 was more negative for incongruent relative to congruent sentence endings, at left electrode sites, only for the TD group.

N100 peak latency analyses showed a significant effect of region $(F(2,38)=4.73, p=.026)$. Subsequent pairwise comparisons showed a trend for earlier peak latency at parietal relative to frontal electrode sites $(p=.065)$.

\subsection{2. $P 200$}

A significant effect of region was observed for P200 peak amplitude $(F(2,38)=3.92, p=.034)$ : more positive P200 amplitudes were found at central relative to parietal electrodes. In addition, a significant sentence condition $\times$ region interaction $(F(2,38)=3.58, p=.038)$ was found: P200 differed between sentence conditions at frontal electrodes only, being more positive for congruent sentence endings. A repeated measures ANOVA testing for hemispheric differences showed a significant sentence condition $\times$ region $\times$ hemisphere $\times$ group interaction $(F(2,38)=3.36, p=.053)$ : a trend for group differences (more positive P200 for WS relative to the TD group) was found at central electrodes of the right hemisphere (C4) for incongruent sentence endings $(p=.098)$.

No significant main effects of group or group interactions were found for P200 latency.

\subsection{3. $N 400$}

As expected, N400 amplitude was more negative for incongruent relative to congruent sentence endings, as evinced by the significant main effect of sentence condition $(F(1,19)=6.75, p=.018)$. The N400 effect had a central distribution, as evinced by a main effect of region $(F(2,38)=11.64, p=.001)$ : amplitudes were significantly more negative at central relative to parietal electrodes. No effects of hemisphere or group were observed.

Analysis of N400 peak latency showed a significant effect of sentence condition $(F(1,19)=15.01, p=.001)$ : N400 peaked earlier for incongruent sentence endings.

Mean N400 peak latency across groups for both sentences' conditions was $308.17 \mathrm{~ms}$, consistent with previous studies showing an earlier onset of N400 in the auditory relative to the visual modality (e.g., Holcomb \& Neville, 1990). In both groups N400 peaked earlier to incongruent sentence endings (see Fig. 3). 


\section{Congruent Sentence Endings}

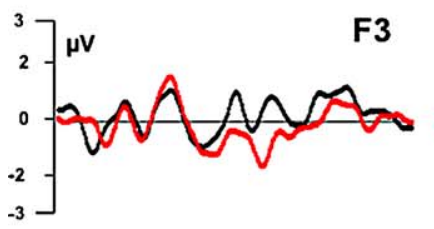

Fz

F4
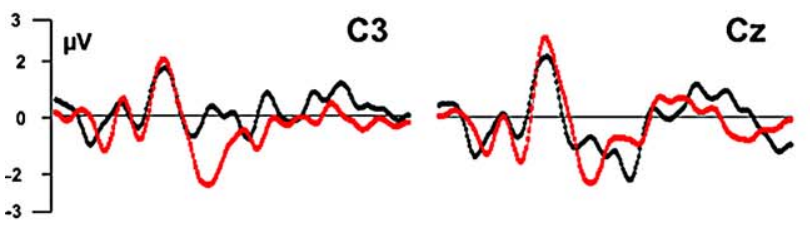

$\mathrm{Cz}$

C4

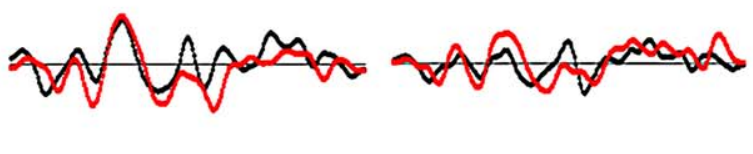

P3

Pz

TD Group
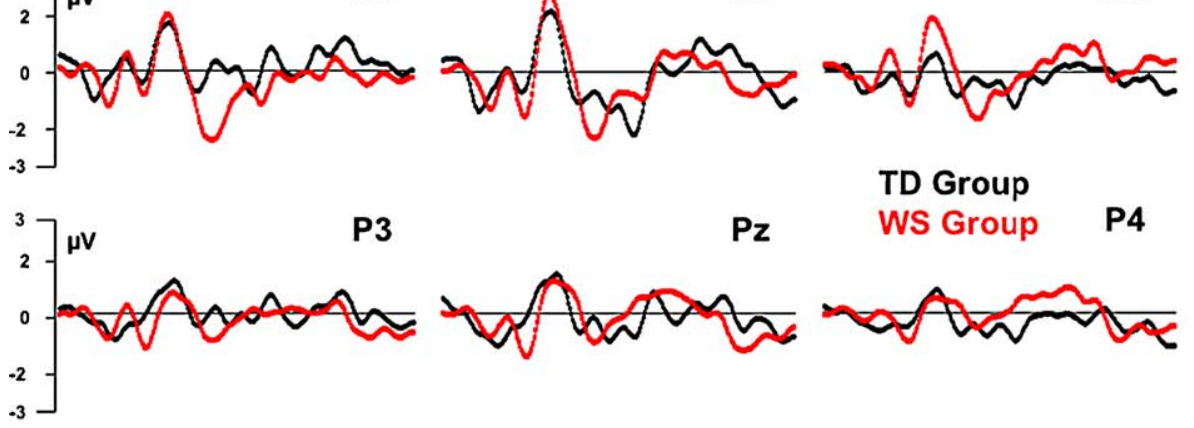

WS Group

P4



$\begin{array}{ccccc}-100 & 100 & 300 \quad 500 & 700 \\ m s e c\end{array}$

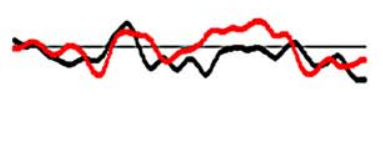

\section{Incongruent Sentence Endings}

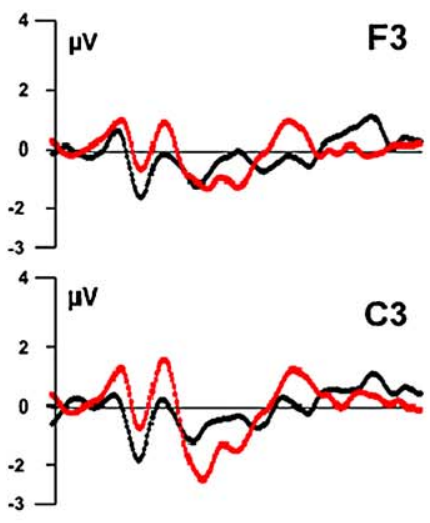

3

Fz

F4
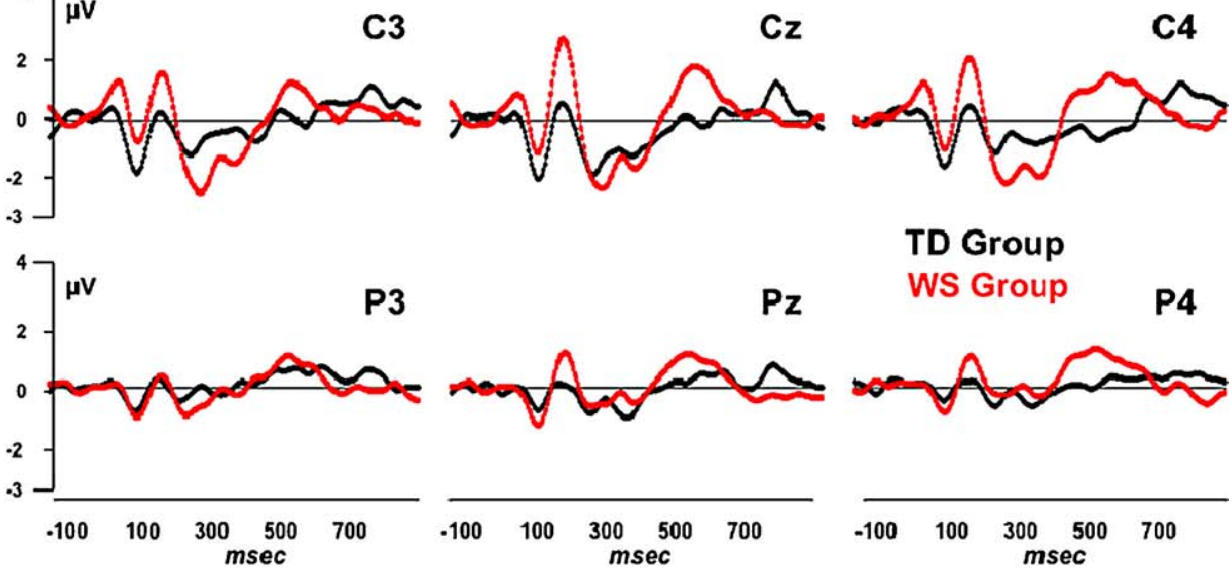

TD Group

WS Group

P4

Fig. 2. (A) Grand average waveforms of TD controls and WS participants recorded to final congruent sentence completions, at frontal, central, and parietal electrode sites. (B) Grand average waveforms of TD controls and WS participants recorded to final incongruent sentence completions, at frontal, central, and parietal electrode sites.

\subsection{4. $P 600$}

There was a significant main effect of group $(F(1,19)=5.63, p=.028)$ for the $500-600$ ms latency window: more positive mean amplitudes were found in WS relative to the TD group. In addition, a significant sentence condition $\times$ region $\times$ group $(F(2,38)=3.89, p=.033)$ interaction was observed: differences between groups were found for incongruent sentence endings at frontal and central electrodes, with more positive amplitudes in WS. Repeated measures ANOVA indicated a 
N400 Peak Latency at Cz

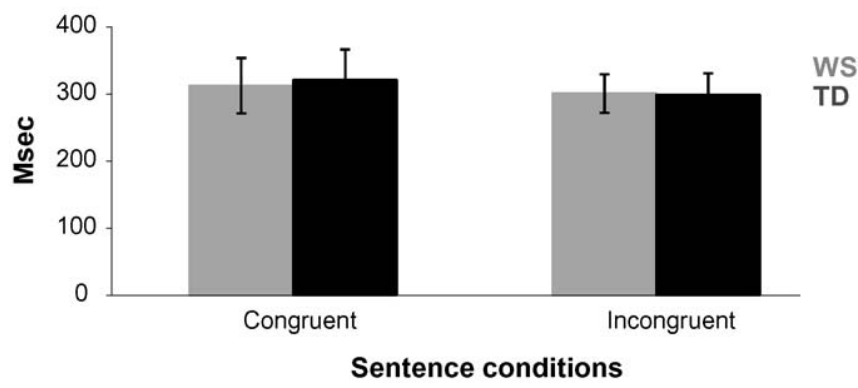

Fig. 3. Mean N400 peak latency for congruent and incongruent final endings in WS and TD groups.

marginally significant sentence condition $\times$ hemisphere interaction $(F(1,19)=4.03, p=.059)$ : amplitudes tended to be more positive for incongruent than for congruent sentence endings at electrodes of the left hemisphere.

No significant effects were observed for the 600-700 ms latency window. However, a significant hemisphere $\times$ group interaction $(F(1,19)=11.34, p=.003)$ was found: in WS group only a larger positivity was found in the right relative to the left hemisphere.

\subsection{Summary}

Overall, results indicate a difference in amplitude for congruent and incongruent sentence endings with an N400 effect showing a central distribution.

Although no main effect of group has been found, ERP waveforms and ANOVAs revealed differences between groups in early components, as indexed by N100 and P200. No group differences were observed for the N400 component. Groups differed significantly in the P600 latency window, with participants with WS showing more positive amplitudes relative to controls. No differences between groups were found in terms of peak latencies.

In addition, the TD group tended to be more accurate than WS individuals in classifying the sentences as congruent or incongruent.

\section{Discussion}

In this study, the ERP method was used to assess the functional organization of semantic memory and online integration of words into their preceding context in WS. A major aim was to analyze the morphology of ERP waveforms elicited by congruent and incongruent sentence endings in participants with WS, in comparison with typically developing controls, in order to best understand potential deviations from typical development.

Groups tended to differ in the number of correct responses for both congruent and incongruent sentence endings, with more errors found in the WS group.

For ERP analyses purposes, four components were selected: N100, P200, N400, and P600 analysed in two latency windows: 500-600 and 600-700 ms. No main effect of group was found for the N100, P200, and N400 components. However, only for the TD group, a significant difference between sentence conditions was found for N100 peak amplitudes, with more negative N100 amplitudes to incongruent sentence endings. A trend for more positive P200 amplitude to incongruent sentence endings was found in the WS group, consistent with previous studies (e.g., Neville et al., 1994).

These early components (N100 and P200) have been proposed to be sensitive to phonological processing (Barnea \& Breznitz, 1998; Liu et al., 2003; Niznikiewicz \& Squires, 1996). In particular, more positive P200 amplitudes for related than to unrelated word pairs have been described in previous studies in normal individuals (Holcomb et al., 1992; Landi \& Perfetti, 2007). It has been suggested that early semantic effects on the P200 may be due to the onset of the N400 (Coulson, Federmeier, Van Petten, \& Kutas, 2005). Since our study did not aim to assess this relationship, future studies should explore the clear relationship between these two components. The current finding may suggest dysfunctional early sensory processes in WS, as previously noted by studies on auditory processing (Bellugi et al., 1994, 1999; Mills et al., 2003; Neville et al., 1994).

Interestingly, no group differences were found for the $\mathrm{N} 400$, although grand averages showed a trend for a smaller difference between congruent and incongruent sentence endings in the WS group.

Overall, the mean latency for the $\mathrm{N} 400$ component was earlier for both groups than what has been commonly reported for the visual modality. These findings are in line with previous studies showing differences in N400 effects dependent on modality of stimuli presentation (visual vs. auditory), with respect to onset latency, duration and scalp distribution (Hagoort 
\& Brown, 2000). In the auditory modality, the N400 effect seems to have an earlier onset (e.g., Holcomb \& Neville, 1990) and a longer duration (e.g., Holcomb \& Neville, 1990). The N400 effect was more pronounced at central and frontal electrode sites, a finding that is consistent with some studies revealing a more sustained negativity over anterior than posterior sites (Holcomb \& Neville, 1990; McCallum, Farmer, \& Pocock, 1984).

As several studies on N400 in typical and atypical groups suggest, this component reflects processes of lexical access and search, as well as of semantic integration (e.g., Brown \& Hagoort, 1993; Federmeier \& Kutas, 1999a,b; Hagoort \& Brown, 2000; Kutas \& Hillyard, 1980, 1984; Rugg et al., 1994). The findings of the current study suggest that these processes occur in a similar way in both groups. The lack of N400 amplitude differences suggests similar semantic integration processes in WS and in typical development. A similar finding was observed also in developmental dyslexia (Sabisch, Hahne, Glass, von Suchodoletz, \& Friederici, 2006), although it does not support previous studies on WS (Neville et al., 1994).

Abnormalities in the N400 morphology have been reported for other neurodevelopmental disorders, in particular an attenuated N400 effect in children at-risk for dyslexia (Torkildsen, Syversen, Simonsen, Moen, \& Lindgren, 2007) and with specific language impairment (Sabisch et al., 2006) or learning disability (Miles \& Stelmack, 1994), and also in adults with learning disability (Plante, van Petten, \& Senkfor, 2000). Larger N400 effects have also been found for children with learning impairment (Neville, Coffey, Holcomb, \& Tallal, 1993). Since most of the literature related to N400 effect in developmental disorders has reported group amplitude differences, it is somewhat unexpected that this difference was not observed in our study. The likely reason for this discrepancy may lie in the differences between experimental designs. For example, some studies used pictures and words that could be congruous or incongruous with the picture content (Plante et al., 2000; Sabisch et al., 2006; Torkildsen et al., 2007), word pairs (Landi \& Perfetti, 2007) or pairs of words and pictures that were related or unrelated (Landi \& Perfetti, 2007). Other studies required that participants read single words or sentences (e.g., Neville et al., 1993).

Given that reading problems are often found in individuals with developmental disorders the experimental task could have introduced an important confound. At the same time, the linguistic complexity of the experimental stimuli may also explain differences in results. In the current study, short sentences with low complexity were used. Furthermore, they were delivered auditorily. Taking into account the present results, it seems that in simple and short semantic contexts, there is a similar neural response to semantically anomalous linguistic stimuli in the WS and TD groups, in the N400 latency window. This is consistent with studies on semantic priming showing the same effects of priming on reaction times of WS individuals (e.g., Tyler et al., 1997) and with the claims of a relative preservation of language processing in WS (see Brock, 2007, for a review). However, when the task becomes more complex and linguistically demanding, differences in semantic processing may be observed.

In addition, in both groups, semantic violations elicited a late positive component. Although no significant differences were found for N400 amplitude, a main effect of group was observed in the 500-600 ms latency window. In normal controls, the P600 component (a positivity that starts around $500 \mathrm{~ms}$ and can continue for more 500 ms) was proposed as an index of processes of sentential judgment (Kolk, Chwilla, van Herten, \& Oor, 2003; see Hagoort, Brown, \& Osterhout, 1999, for a review). Previous studies with normal population, in which the task was to judge the congruency of a word taking into account its preceding context (e.g., Holcomb et al., 1992), also found a late positivity that seems to be related to post-lexical wrap-up processes (e.g., Juottonen, Revonsuo, \& Lang, 1996). P600 has been considered an index of the integration of syntactic and semantic information into a coherent representation (Friederici, Hahne, \& Mecklinger, 1996; Friederici, Pfeifer, \& Hahne, 1993; Hoeks, Stowe, \& Doedens, 2004; Kim \& Osterhout, 2005; Kolk et al., 2003; Kuperberg, Kreher, Sitnikova, Caplan, \& Holcomb, 2007; Nieuwland \& van Berkum, 2005; van Herten, Chwilla, \& Kolk, 2006; van Herten, Kolk, \& Chwilla, 2005). Therefore, the more positive-going waveform, observed around 600 ms for the WS group relative to typically developing controls, particularly for incongruent sentence endings, may suggest high semantic integration demands, probably reflecting additional difficulties in processes of semantic integration and re-analysis, or an increased effort in performing the judgment task, consistent with the higher error rates observed in the behavioral task.

This finding seems to be consistent with the suggestion of Tyler et al. (1997) that a preserved access to semantic information may coexist with deficits in the integration of semantic information in sentence comprehension in WS, as indexed by abnormalities in later integrative ERP components and by behavioral measures such as narrative integration (Reilly, Losh, Bellugi, \& Wulfeck, 2004; Stojanovik, Perkins, \& Howard, 2004).

Together, the current findings showed atypicalities in both early (N100 and P200) and late (P600) ERP components, supporting the hypothesis that abnormalities in early sensory (auditory) processing also have an influence on language relevant systems (e.g., semantic processing), as suggested by a previous study (Neville et al., 1994).

The current findings also confirm the importance of combining methodologies for a better understanding of semantic processing. In fact, behavioral studies only provide a limited source of information on language and communication difficulties in WS. Functional measures can overcome the limitation of reaction time or accuracy measures, allowing the study of brain processes before the response is made or even in its absence (Niznikiewicz et al., 1997). The present results can offer a new perspective on language processing difficulties in individuals with WS, aiding the development of more efficient and targeted intervention strategies for neurocognitive rehabilitation in these participants. More studies are needed for a better understanding of the neural processes that underlie semantic processing in this disorder. Future studies should also include larger samples and additional control groups (e.g., other neurodevelopmental disorders), for a better understanding of the specificities of semantic processing difficulties in WS. 


\section{Acknowledgments}

This research was supported by a Doctoral Grant (SFRH/BD/35882/2007) awarded to the first author, as well as by the grant PIC/IC/83290/2007, both from FCT (Fundação para a Ciência e a Tecnologia), in Portugal.

The authors would like to thank all the participants who participated in the study and all who helped to recruit the participants. Also, a special acknowledgement for the members of the Portuguese Williams Syndrome Association, for their continuous support.

\section{Appendix A}

Examples of experimental sentences in both conditions (congruent and incongruent endings). The original sentences are presented in first place, followed by a translation in English.

\begin{tabular}{|c|c|}
\hline Congruent sentence & Incongruent sentence \\
\hline A menina penteia o cabelo & A menina penteia o biscoito \\
\hline The girl curls her hair & The girl curls her biscuit \\
\hline A cozinheira acende o fogão & A cozinheira acende o gato \\
\hline The cook turns on the oven & The cook turns on the cat \\
\hline A mulher veste uma saia & A mulher veste uma pêra \\
\hline The woman wears a skirt & The woman wears a pear \\
\hline A criança bebe o leite & A criança bebe o balão \\
\hline The child drinks the milk & The child drinks the balloon \\
\hline A mãe lê um livro & A mãe lê um chapéu \\
\hline The mother reads a book & The mother reads a hat \\
\hline A escritora escreve uma história & A escritora escreve uma amêndoa \\
\hline The writer writes a story & The writer writes an almond \\
\hline A empregada arruma a casa & A empregada arruma a testa \\
\hline The waitress cleans the house & The waitress cleans the forehead \\
\hline A meia aquece o pé & A meia aquece o céu \\
\hline The sock warms the foot up & The sock warms the sky up \\
\hline O mecânico compõe o carro & O mecânico compõe o atum \\
\hline The mechanic fixes the car & The mechanic fixes the tuna \\
\hline O motorista conduz o autocarro & O motorista conduz o alfinete \\
\hline The motorist drives the bus & The motorist drives the pin \\
\hline O rapaz calça o sapato & O rapaz calça o caderno \\
\hline The boy wears the shoes & The boy wears the notebook \\
\hline O coelho come uma cenoura & O coelho come uma máquina \\
\hline The rabbit eats a carrot & The rabbit eats a machine \\
\hline O trolha constrói uma casa & O trolha constrói uma neve \\
\hline The builder builds the house & The builder builds the snow \\
\hline A almofada enfeita a cama & A almofada enfeita a boca \\
\hline The pillow decorates the bed & The pillow decorates the mouth \\
\hline O professor ensina o estudante & O professor ensina o amendoim \\
\hline The professor teaches the student & The professor teaches the peanut \\
\hline
\end{tabular}

\section{References}

Anderson, J. E., \& Holcomb, P. J. (1995). Auditory and visual semantic priming using different stimulus onset asynchronies: An event-related brain potential study. Psychophysiology, 32, 177-190.

Barnea, A., \& Breznitz, Z. (1998). Phonological and orthographic processing of Hebrew words: Electrophysiological aspects. Journal of Genetic Psychology, 159, 492504.

Bellugi, U., Bihrle, A., Jernigan, T., Trauner, D., \& Doherty, S. (1990). Neuropsychological, neurological, and neuroanatomical profile of Williams syndrome. American Journal of Medical Genetics Supplement, 6, 115-125. 
Bellugi, U., Bihrle, A., Neville, H., Jernigan, T., \& Doherty, S. (1992). Language, cognition, and brain organization in a neurodevelopmental disorder. In M. Gunnar \& C. Nelson (Eds.), Developmental behavioral neuroscience (pp. 201-232). Hillsdale, NJ: Lawrence Erlbaum Associates.

Bellugi, U., Lichtenberger, L., Jones, W., Lai, Z., \& St. George, M. (2000). The neurocognitive profile of Williams syndrome: A complex pattern of strengths and weaknesses. In U. Bellugi \& M. St. George (Eds.), Journey from cognition to brain to genes: Perspectives from Williams syndrome. Cambridge, MA: MIT Press.

Bellugi, U., Marks, S., Bihrle, A., \& Sabo, H. (1988). Dissociation between language and cognitive function in Williams syndrome. In D. Bishop \& K. Mogford (Eds.), Language development in exceptional circumstances. Edinburgh: Churchill Livingstone.

Bellugi, U., Wang, P. P., \& Jernigan, T. L. (1994). Williams syndrome: An unusual neuropsyhological profile. In S. Broman \& J. Grafman (Eds.), Atypical cognitive deficits in developmental disorders: Implications for brain function. Hillsdale, NJ: Lawrence Erlbaum Associates.

Besson, M., \& Macar, F. (1986). Visual and auditory event-related potentials elicited by linguistic and non-linguistic incongruities. Neuroscience Letters, 63, 109114.

Brock, J. (2007). Language abilities in Williams syndrome: A critical review. Developmental Psychopathology, 19, 97-127.

Bromberg, H. S., Ullman, M., Marcus, G., Kelly, K. B., \& Levine, K. (1995). A dissociation of lexical memory and grammar in Williams syndrome: Evidence from inflectional morphology. Genetic Counseling, Special Issue, 6, 166-167.

Brown, C., \& Hagoort, P. (1993). The processing nature of the N400: Evidence from masked priming. Journal of Cognitive Neurosciences, 5, 34-44.

Castro, S. L., Caló, S., Gomes, I., Kay, J., Lesser, R., \& Coltheart, M. (2007). PALPA-P, Provas de Avaliação da Linguagem e da Afasia em Português [Tasks for the assessment of language processing and aphasia in Portuguese, PALPA-P]. Lisboa: CEGOC.

Coch, D., Maron, L., Wolf, M., \& Holcomb, P. J. (2002). Word and picture processing in children: An event-related potential study. Developmental Neuropsychology, 22, 373-406.

Coulson, S., Federmeier, K. D., Van Petten, C., \& Kutas, M. (2005). Right hemisphere sensitivity to word- and sentence-level context: Evidence from event-related brain potentials. Journal of Experimental Psychology: Learning, Memory, and Cognition, 31, 129-147.

Cummings, A., Ceponiene, R., Dick, F., Saygin, A. P., \& Townsend, J. (2008). A developmental ERP study of verbal and non-verbal semantic processing. Brain Research, 1208, 137-149.

Federmeier, K. D., \& Kutas, M. (1999a). Right words and left words: Electrophysiological evidence for hemispheric differences in meaning processing. Brain Research Cognitive Brain Research, 8, 373-392.

Federmeier, K. D., \& Kutas, M. (1999b). A rose by any other name: Long-term memory structure and sentence processing. Journal of Memory and Language, 41, 469495.

Federmeier, K. D., \& Kutas, M. (2002). Picture the difference: Electrophysiological investigations of picture processing in the two cerebral hemispheres. Neuropsychologia, 40, 730-747.

Friederici, A. D., Hahne, A., \& Mecklinger, A. (1996). The temporal structure of syntactic parsing: Early and late ERP effects elicited by syntactic anomalies. Journal of Experimental Psychology: Learning, Memory, Cognition, 22, 1-31.

Friederici, A. D., Pfeifer, E., \& Hahne, A. (1993). Event-related brain potentials during natural speech processing: Effects of semantic, morphological and syntactic violations. Cognitive Brain Research, 1, 183-192.

Friedman, D., Simson, A., Ritter, W., \& Rapin, Y. (1975). The late positive component (P300) and information processing in sentences. Electroencephalography and Clinical Neurophysiology, 31, 255-262.

Geisser, S., \& Greenhouse, S. (1959). On methods in the analysis of profile data. Psychometrica, 24, 95-112.

Gonçalves, O. F., Pérez, A., Henriques, M., Prieto, M., Lima, M., Siebert, M., et al. (2004). Funcionamento cognitivo e produção narrativa no Síndrome de Williams: Congruência ou dissociação neurocognitiva? (Cognitive functioning and narrative production in Williams syndrome: Congruence or neurocognitive dissociation). International Journal of Clinical and Health Psychology, 4, 623-638.

Gonçalves, O. F., Pinheiro, A. P., Sampaio, A., Sousa, N., Férnandez, M., \& Henriques, M. (2010). The narrative profile in Williams Syndrome: There is more to storytelling than just telling a story. The British Journal of Developmental Disabilities, 56(111), 89-109.

Graffar, M. (1956). Une méthode de classification sociale d'échantillons de population. Courier, 6, 455.

Grant, J., Valian, V., \& Karmiloff-Smith, A. (2002). A study of relative clauses in Williams syndrome. Journal of Child Language, 29, 403-416.

Gratton, G., Coles, M. G., \& Donchin, E. (1983). A new method for off-line removal of ocular artifact. Electroencephalography and Clinical Neurophysiology, 55, 468-484.

Hagoort, P., \& Brown, C. M. (2000). ERP effects of listening to speech: Semantic ERP effects. Neuropsychologia, 38, 1518-1530.

Hagoort, P., Brown, C. M., \& Osterhout, L. (1999). The neurocognition of syntactic processing. In C. M. Brown \& P. Hagoort (Eds.), The neurocognition of language (pp. 273-316). Oxford, UK: Oxford University Press.

Hahne, A., Eckstein, K., \& Friederici, A. D. (2004). Brain signatures of syntactic and semantic processes during children's language development. Journal of Cognitive Neuroscience, 16, 1302-1318.

Halgren, E. (1990). Insights from evoked potentials into the neuropsychological mechanisms of reading. In A. B. Scheibel \& A. F. Wechsler (Eds.), Neurobiology of higher cognitive function (pp. 103-150). Hove: Lawrence Erlbaum.

Heinze, H. J., Muente, T. F., \& Kutas, M. (1998). Context effects in a category verification task as assessed by event-related brain potential (ERP) measures. Biological Psychology, 47, 121-135

Hoeks, J. C. J., Stowe, L. A., \& Doedens, G. (2004). Seeing words in context: The interaction of lexical and sentence level information during reading. Cognitive Brain Research, 19, 59-73.

Holcomb, P. J., Coffey, S. A., \& Neville, H. J. (1992). Visual and auditory sentence processing: A developmental analysis using event-related brain potentials. Developmental Neuropsychology, 8, 203-241.

Holcomb, P. J., \& Neville, H. J. (1990). Auditory and visual semantic priming in lexical decision: A comparison using event-related brain potentials. Language and Cognitive Processes, 5, 281-312.

Hsu, C., Karmiloff-Smith, A., Tzeng, O., Chin, R., \& Wang, H. (2007). Semantic knowledge in Williams syndrome: Insights from comparing behavioural and brain processes in false memory tasks. Proceedings of the 6th IEEE International Conference on Development and Learning (ICDL), 6, 48-52.

Jarrold, C., Baddeley, A. D., \& Hewes, A. K. (1998). Verbal and nonverbal abilities in the Williams syndrome phenotype: Evidence for diverging developmental trajectories. Journal of Child Psychology and Psychiatry, 39, 511-523.

Jarrold, C., Hartley, S. J., Phillips, C., \& Baddeley, A. D. (2000). Word fluency in Williams syndrome: Evidence for unusual semantic organization. Cognitive Neuropsychiatry, 5, 293-319.

Jasper, H. (1958). The ten-twenty system of the international federation. Electroencephalography and Clinical Neurophysiology, 10, 371-375

Johnson, S. C., \& Carey, S. (1998). Knowledge enrichment and conceptual change in folkbiology: Evidence from Williams syndrome. Cognitive Psychology, 37, 156-200.

Jones, W., Bellugi, U., Lai, Z., Chiles, M., Reilly, J., Lincoln, A, II. et al. (2000). Hypersociability in Williams syndrome. Journal of Cognitive Neuroscience, 12 , $30-46$.

Juottonen, K., Revonsuo, A., \& Lang, H. (1996). Dissimilar age influences on two ERP waveforms (LPC and N400) reflecting semantic context effect. Cognitive Brain Research, 4, 99-107.

Kim, A., \& Osterhout, L. (2005). The independence of combinatory semantic processing: Evidence from event-related potentials. Journal of Memory and Language, $52,205-225$.

Kolk, H. H. J., Chwilla, D. J., van Herten, M., \& Oor, P. J. (2003). Structure and limited capacity in verbal working memory: A study with event-related potentials. Brain and Language, 85, 1-36.

Korenberg, J. R., Chen, X. N., Hirota, H., Lai, Z., Bellugi, U., Burian, D., et al. (2000). VI. Genome structure and cognitive map of Williams syndrome. Journal of Cognitive Neuroscience, $12,89-107$.

Kramer, A., \& Donchin, E. (1987). Brain potentials as indices of ortographic and phonological interaction during word matching. Journal of Experimental Psychology: Learning, Memory, and Cognition, 13, 76-86.

Kuperberg, G. R., Kreher, D. A., Sitnikova, T., Caplan, D. N., \& Holcomb, P. J. (2007). The role of animacy and thematic relationships in processing active English sentence: Evidence from event-related potentials. Brain and Language, 100, 223-237. 
Kutas, M., \& Federmeier, K. D. (2000). Electrophysiology reveals semantic memory use in language comprehension. Trends in Cognitive Sciences, 4, 463-470.

Kutas, M., \& Hillyard, S. A. (1980). Reading senseless sentences: Brain potentials reflect semantic incongruity. Science, $207,203-205$.

Kutas, M., \& Hillyard, S. A. (1984). Brain potentials during reading reflect word expectancy and semantic association. Nature, $307,161-163$.

Kutas, M., \& Iragui, V. (1998). The N400 in a semantic categorization task across 6 decades. Electroencephalography and Clinical Neurophysiology, 108, 456-471.

Laing, E., Butterworth, G., Ansari, D., Gsödl, M., Longhi, E., Panagiotaki, G., et al. (2002). Atypical development of language and social communication in toddlers with Williams syndrome. Developmental Science, 5, 233-246.

Landau, B., \& Zukowski, A. (2003). Objects, motions, and paths: Spatial language in children with Williams syndrome. Developmental Neuropsychology, 23, 105137.

Landi, N., \& Perfetti, C. A. (2007). An electrophysiological investigation of semantic and phonological processing in skilled and less-skilled comprehenders. Brain and Language, 102, 30-45.

Lau, E. F., Phillips, C., \& Poeppel, D. (2008). A cortical network for semantics: (De)constructing the N400. Nature Neuroscience Reviews, 9, 920-933.

Laws, G., \& Bishop, D. (2004). Pragmatic language impairment and social deficits in Williams syndrome: A comparison with Down's syndrome and specific language impairment. International Journal of Language and Communication Disorders, 39, 45-64.

Liu, Y., Perfetti, C. A., \& Hart, L. (2003). ERP evidence for the time course of graphic, phonological, and semantic information in Chinese meaning and pronunciation decisions. Journal of Experimental Psychology: Learning, Memory, and Cognition, 29, 1231-1247.

Lukács, A., Pléh, C., \& Racsmány, M. (2004). Language in Hungarian children with Williams syndrome. In S. Bartke \& J. Siegmüller (Eds.), Williams syndrome across languages. (pp. 187-220). Amsterdam: John Benjamins.

Marques, J. F., Fonseca, F. L., Morais, A. S., \& Pinto, I. A. (2007). Estimated age of acquisition norms for 834 Portuguese nouns and their relation with other psycholinguistic variables. Behavior Research Methods, 39, 439-444.

Martens, M. A., Wilson, S. J., \& Reutens, D. C. (2008). Research review: Williams syndrome: A critical review of the cognitive, behavioral, and neuroanatomical phenotype. Journal of Child Psychology and Psychiatry, 49, 576-608.

McCallum, W. C., Farmer, S. F., \& Pocock, P. V. (1984). The effects of physical and semantic incongruities on auditory event-related potentials. Electroencephalography and Clinical Neurophysiology, 59, 477-488.

Mervis, C. B. (2003). Williams syndrome: 15 years of psychological research. Developmental Neuropsychology, $23,1-12$.

Mervis, C. B., \& Bertrand, J. (1997). Developmental relations between cognition and language. In L. B. Adamson \& M. A. Romski (Eds.), Communication and language acquisition: Discoveries from atypical development. Baltimore, MD: Paul Brookes.

Mervis, C. B., Morris, C. A., Klein-Tasman, B. P., Bertrand, J., Kwitny, S., Appelbaum, L. G., et al. (2003). Attentional characteristics of infants and toddlers with Williams syndrome during triadic interactions. Developmental Neuropsychology, 23, 243-268.

Mervis, C. B., \& Robinson, B. F. (2000). Expressive vocabulary ability of toddlers with Williams syndrome or Down syndrome: A comparison. Developmental Neuropsychology, 17, 111-126.

Miles, J., \& Stelmack, R. M. (1994). Learning disability subtypes and the effects of auditory and visual priming on visual event-related potentials to words. Journal of Clinical and Experimental Neuropsychology, 16, 43-64.

Mills, D., Llamas, T., St George, M., Doyle, T. F., Neville, H., \& Korenberg, J. R. (2003). Electrophysiological signatures of abnormal auditory language processing in infants, children and adults with Williams syndrome. San Diego: Institute for Neural Computation, University of California.

Nascimento, M. F. B., Casteleiro, J. M., Marques, M. L. G., Barreto, F., \& Amaro, R. (no date). Corlex: Léxico de frequências do Português [Lexical DataBase]. Available in http://www.clul.ul.pt.

Neville, H., Mills, D. L., \& Bellugi, U. (1994). Effects of altered auditory sensitivity and age of language acquisition on the development of language-relevant neural systems: Preliminary studies of Williams syndrome. In S. Broman \& J. Grafman (Eds.), Atypical cognitive deficits in developmental disorders: Implications for brain function (pp. 67-83). Hillsdale, NJ: Erlbaum.

Neville, H. J., Coffey, S. A., Holcomb, P. J., \& Tallal, P. (1993). The neurobiology of sensory and language processing in language-impaired children. Journal of Cognitive Neuroscience, 5, 235-253.

Nieuwland, M. S., \& van Berkum, J. J. A. (2005). Testing the limits of the semantic illusion phenomenon: ERPs reveal temporary semantic change deafness in discourse comprehension. Cognitive Brain Research, 24, 691-701.

Niznikiewicz, M., \& Squires, N. K. (1996). Phonological processing and the role of strategy in silent reading: Behavioral and electrophysiological evidence. Brain and Language, 52, 342-364.

Niznikiewicz, M. A., O’Donnell, B. F., Nestor, P. G., Smith, L., Law, S., Karapelou, M., et al. (1997). ERP assessment of visual and auditory language processing in schizophrenia. Journal of Abnormal Psychology, 106, 85-94.

Oldfield, R. C. (1971). The assessment and analysis of handedness: The Edinburgh inventory. Neuropsychologia, 9, 97-113.

Osterhout, L., \& Holcomb, P. (1992). Event related brain potential elicited by syntactic anomaly. Journal of Memory and Language, 31, 1-22.

Phillips, C. E., Jarrold, C., Baddeley, A. D., Grant, J., \& Karmiloff-Smith, A. (2004). Comprehension of spatial language terms in Williams syndrome: Evidence for an interaction between domains of strength and weakness. Cortex, 40, 85-101.

Pinker, S. (1994). The language instinct: How the mind creates language. New York: HarperCollins.

Plante, E., Van Petten, C., \& Senkfor, A. J. (2000). Electrophysiological dissociation between verbal and nonverbal semantic processing in learning disabled adults. Neuropsychologia, 38, 1669-1684.

Pléh, C., Lukács, Á. , \& Racsmány, M. (2003). Morphological patterns in Hungarian children with Williams syndrome and the rule debates. Brain and Language, 86, 377-383.

Reilly, J., Klima, E. S., \& Bellugi, U. (1991). Once more with feeling: Affect and language in atypical populations. Development and Psychopathology, 2, 367-391.

Reilly, J., Losh, M., Bellugi, U., \& Wulfeck, B. (2004). “Frog, where are you?" Narratives in children with specific language impairment, early focal brain injury, and Williams syndrome. Brain and Language, 88, 229-247.

Rossen, M., Klima, E. S., Bellugi, U., Bihrle, A., \& Jones, W. (1996). Interaction between language and cognition: Evidence from Williams syndrome. In J. H. Beitchman, N. Cohen, M. Konstantareas, \& R. Tannock (Eds.), Language, learning, and behavior disorders: Developmental, biological, and clinical perspectives. (pp. 367-392). New York: Cambridge University Press.

Rugg, M. D., Doyle, M. C., \& Holdstock, J. S. (1994). Modulation of event-related brain potentials by word repetition: Effects of local context. Psychophysiology, 31, $447-459$.

Sabisch, B., Hahne, A., Glass, E., von Suchodoletz, W., \& Friederici, A. D. (2006). Lexical semantic processes in children with specific language impairment. Neuroreport, 17, 1511-1514.

Scott, P., Mervis, C. B., Bertrand, J., Klein, B. P., Armstrong, S. C., \& Ford, A. L. (1995). Semantic organization and word fluency in 9- and 10-year-old children with Williams syndrome. Genetic Counseling, 6, 172-173.

St. George, M., Mills, D. L., \& Bellugi, U. (2000). ERPs during auditory language comprehension in Williams syndrome. The effects of word frequency, imageability and length on word class. Neuroimage, 11, 357.

Stevens, T., \& Karmiloff-Smith, A. (1997). Word learning in a special population: Do individuals with Williams syndrome obey lexical constraints? Journal of Child Language, 24, 737-765.

Stojanovik, V., Perkins, M., \& Howard, S. (2004). Williams syndrome and specific language impairment do not support claims for developmental double dissociations and innate modularity. Journal of Neurolinguistics, 17, 403-424.

Sullivan, K., Winner, E., \& Tager-Flusberg, H. (2003). Can adolescents with Williams syndrome tell the difference between lies and jokes? Developmental Neuropsychology, 23, 85-103.

Temple, C. M., Almazan, M., \& Sherwood, S. (2002). Lexical skills in Williams syndrome: A cognitive neuropsychological analysis. Journal of Neurolinguistics, 15, $463-495$.

Torkildsen, J. K., Syversen, G., Simonsen, H. G., Moen, I., \& Lindgren, M. (2007). Brain responses to lexical-semantic priming in children at-risk for dyslexia. Brain and Language, 102, 243-261. 
Tyler, L. K., Karmiloff-Smith, A., Voice, J. K., Stevens, T., Grant, J., Udwin, O., et al. (1997). Do individuals with Williams syndrome have bizarre semantics? Evidence for lexical organization using an on-line task. Cortex, 33, 515-527.

van den Brink, D., Brown, C. M., \& Hagoort, P. (2001). Electrophysiological evidence for early contextual influences during spoken-word recognition: N200 versus N400 effects. Journal of Cognitive Neuroscience, 13, 967-985.

van Herten, M., Chwilla, D. J., \& Kolk, H. H. J. (2006). When heuristics clash with parsing routines: ERP evidence for conflict monitoring in sentence perception. Journal of Cognitive Neuroscience, 18, 1181-1197.

van Herten, M., Kolk, H. H. J., \& Chwilla, D. J. (2005). An ERP study of P600 effects elicited by semantic anomalies. Cognitive Brain Research, 22, $241-255$.

Van Petten, C. (1993). A comparison of lexical and sentence-level context effects in event-related potentials. Language and Cognitive Processes, 8, 485-531.

Van Petten, C., Coulson, S., Rubin, S., Plante, E., \& Parks, M. (1999). Time course of word identification and semantic integration in spoken language. Journal of Experimental Psychology: Learning, Memory, and Cognition, 25, 394-417.

Vicari, S., Bates, E., Caselli, M. C., Pasqualetti, P., Gagliardi, C., Tonucci, F., et al. (2004). Neuropsychological profile of Italians with Williams syndrome: An example of a dissociation between language and cognition? Journal of the International Neuropsychological Society, 10, 862-876.

Volterra, V., Capirci, O., Pezzini, G., Sabbadini, L., \& Vicari, S. (1996). Linguistic abilities in Italian children with Williams syndrome. Cortex, 32, 663-677.

Wang, P. P., \& Bellugi, U. (1993). Williams syndrome. Down syndrome, and cognitive neuroscience. American Journal of Diseases of Children, 147, $1246-1251$.

Wechsler, D. (1991). Wechsler Intelligence Scale for Children (3rd edition). Manual San Antonio: Psychological Corporation.

Wechsler, D. (1997). WAIS-III: Manual. London: The Psychological Corporation.

West, W. C., \& Holcomb, P. J. (2002). Event-related potentials during discourse-level semantic integration of complex pictures. Brain Research. Cognitive Brain Research, 13, 363-375.

Willems, R. M., Özyürek, A., \& Hagoort, P. (2008). Seeing and hearing meaning: ERP and fMRI evidence of word versus picture integration into a sentence context. Journal of Cognitive Neuroscience, 20, 1235-1249.

Ypsilanti, A., Grouios, G., Alevriadou, A., \& Tsapkini, K. (2005). Expressive and receptive vocabulary in children with Williams and Down syndromes. Journal of Intellectual Disability Research, 49, 353-364.

Ypsilanti, A., Grouios, G., Zikouli, A., \& Hatzinikolaou, K. (2006). Speed of naming in children with Williams and Down syndromes. Journal of Intellectual \& Developmental Disability, 31, 87-94. 